Article

\title{
A Comparative Study on the Effects of Passivation Methods on the Carrier Lifetime of RIE and MACE Silicon Micropillars
}

\author{
Amal Kabalan $\mathbb{D}$ \\ Department of Electrical and Computer Engineering, Bucknell University, Lewisburg, PA 17837, USA; \\ amal.kabalan@bucknell.edu
}

Received: 7 March 2019; Accepted: 25 April 2019; Published: 30 April 2019

\begin{abstract}
Silicon micropillars have been suggested as one of the techniques for improving the efficiency of devices. Fabrication of micropillars has been done in several ways-Metal Assisted Chemical Etching (MACE) and Reactive Ion Etching (RIE) being the most popular techniques. These techniques include etching through the surface which results in surface damage that affects the carrier lifetime. This paper presents a study that compares the carrier lifetime of micropillars fabricated using RIE and MACE methods. It also looks at increasing carrier lifetime by surface treatment using three main approaches: surface passivation by depositing $\mathrm{Al}_{2} \mathrm{O}_{3}$, surface passivation by depositing $\mathrm{SiO}_{2} / \mathrm{SiN}$, and surface passivation by etching using $\mathrm{KOH}$ and Hydrofluoric Nitric Acetic (HNA) solution. It was concluded that passivating with $\mathrm{SiO}_{2}$ and $\mathrm{SiN}$ results in the highest carrier lifetime on the MACE and RIE pillars.
\end{abstract}

Keywords: silicon; micropillars; passivation; reactive ion etching; and metal assisted ion etching

\section{Introduction}

Micro and nanoscale structures have improved the performance of many electronic devices such as solar cells [1,2], light emitting diodes [3], detectors [4], and batteries [5]. Patterning the surface of planar silicon with micropillars results in broadband antireflection [6-8], enhanced light trapping $[9,10]$ and high carrier collection efficiency by separating the path for light absorption and carrier collection using a core-shell p-n junction and increasing the junction area [11]. At the same time, the large junction area and surface area on the pillar arrays compared to traditional planar junction silicon solar cells makes it challenging to fabricate high performance devices due to an increase in surface defects. This makes the choice of the micropillar fabrication technique very critical since it has an impact on the quality of the surface of the pillars. Micropillars can be formed using a bottom-up approach such as the metal-catalyzed Vapor-Liquid-Solid (VLS) technique or using top-down approaches such as Metal Assisted Chemical Etching (MACE) and Reactive Ion Etching (RIE), which are the most commonly used $[12,13]$.

Over the past few years, RIE has been used extensively for surface texturing of silicon, mainly due to its relative ease in controlling process parameters which means that good reliability and reproducibility can be obtained [14]. In the RIE process a silicon substrate is put in contact with a noble metal mask (gold or silver). The substrate is placed on a high frequency driven and dc-biased electrode [15]. After ignition of the plasma, a capacitive coupled electrode acquires a negative charge because the electron mobility is much greater than that of the ions. Glow-discharge plasma is used to generate the gas-phase etching environment, which consists of positive and negative ions, electrons, radicals, and neutrals from a feed gas (CF4). The material on the electrode is thus exposed to energetic bombardment by positive ions. At the same time chemical reactions between radicals and neutrals 
and the material being etched (silicon) occur at the surface and produce either volatile species or their precursors. Also, positive ions are accelerated across the plasma sheath and remove material by sputtering. The combination of the chemical activity of reactive species and sputtering can result in much higher material erosion rates in the vertical than in the lateral direction which forms the sharp edges of the pillars [16].

MACE is a wet etching technique that produces high aspect ratio semiconductor micro- and nanostructures. This technique has been used in photonic, photovoltaic, and diffusion membrane applications [17]. To fabricate micro- or nano-features using this application, metal particles or films are deposited at the silicon surface prior to chemical etching to enhance silicon dissolution. This step can be done using different techniques such as sputtering, thermal evaporation, electrochemical deposition. or electroless deposition in HF solutions [18]. Wet etching of most semiconductors occurs isotropically. This usually results in the loss of lateral resolution defined by the used mask. One of the exceptions is the use of crystal dependent wet etch. For example, the etch rate of $\mathrm{Si}$ (111) in $\mathrm{KOH}$ solution can be over two orders of magnitude slower than $\mathrm{Si}$ (110); therefore a $\mathrm{Si}(110)$ surface can be etched to produce deep trenches with (111) sidewalls [18]. Both RIE and MACE etching methods result in surface damage that affects the carrier lifetimes.

Surface damage has been mitigated using various surface passivation methods that either etch away the damaged surface using material such as $\mathrm{KOH}$ or passivate the surface using material such as $\mathrm{Al}_{2} \mathrm{O}_{3}$ [19], $\mathrm{SiO}_{2}$ [20], or $\mathrm{SiN}$ [21] to passivate dangling bonds. The effect of the above approaches varies in nature and the intent of this paper is to quantify the surface damage and investigate the best passivation method that provides the highest carrier lifetime. First the paper will present the details of the fabrication methods of the micropillars. The paper will then discuss the steps of the passivation methods and the measurements obtained. Finally the paper will present a discussion on the results.

\section{Materials and Methods}

Two silicon micropillar samples were studied. P-type $\mathrm{Cz}$ (100) wafers with resistivity of 5-10 $\Omega$-cm were used for the experiments. The first was fabricated using RIE and the second using MACE. The procedure for fabricating RIE is as follows. P-type silicon wafer (11-22 $\mu \mathrm{m})$ was used to fabricate the vertical silicon micropillars using dry etching. The microdisk arrays were patterned in LOR3A and Shipley S1805 photoresist using photolithography. After the pattern was developed, aluminum was deposited to a thickness of $100 \mathrm{~nm}$ and lifted off to leave aluminum microdisk arrays on the starting Si wafer. A highly doped n-type conformal shell for the crystalline $\mathrm{p}-\mathrm{n}$ junction was formed using the spin-on doping (SOD) method. After spinning an n-type doping source (P509, Filmtronics, Inc.) on a dummy Si wafer, we position the device wafer containing the micropillars so that it faces the dummy wafer coated with doping source, and then anneal the pair of wafers at high temperature $\left(900-950^{\circ} \mathrm{C}\right.$ ) for $10 \mathrm{~min}$ in a $20 \% \mathrm{O}_{2}$ and $80 \% \mathrm{~N}_{2}$ environment. The process of the MACE fabrication is as follows. Au was used as the etch catalyst because it has been known to produce a solid and smooth surface compared with other catalysts [22]. The mesh patterns were generated by soft lithography with a liftoff process. The MACE solution to produce solid micropillar was a mixture of concentrated $\mathrm{HF}, \mathrm{H}_{2} \mathrm{O}_{2}$, and ethanol. The oxidizing agent generates free holes $(\mathrm{h}+)$ when catalyzed by the metal. The holes oxidize Si at the metal-Si interface and HF dissolves oxidized Si [23]. As a result the material directly underneath the metal is preferentially removed and the metal descends into the semiconductor.

Figure 1 represents the RIE micropillars with a diameter of $2.2 \mu \mathrm{m}$ and a spacing of $1.75 \mu \mathrm{m}$. Figure 2 represents the MACE micropillars with diameter of $2.1 \mu \mathrm{m}$ and spacing of $2 \mu \mathrm{m}$. All samples were rinsed with deionized water and dipped in an HF solution ( $45 \%$ for $5 \mathrm{~min}$ ) before any surface treatment. Surface treatment with $\mathrm{KOH}$ was performed by rinsing the sample with deionized water and dipping the samples in a $\mathrm{KOH}$ solution with concentration of $45 \%$ for $30 \mathrm{~s}$. Surface treatment for Hydrofluoric Nitric Acetic (HNA) solution was performed by rinsing the sample with deionized water and dipping the sample in 50\% HNA solution for $5 \mathrm{~s}$. The samples were passivated with $\mathrm{Al}_{2} \mathrm{O}_{3}$ by depositing $20 \mathrm{~nm}$ of the film using the atomic layer deposition approach and annealing the sample at $350^{\circ} \mathrm{C}$ for $10 \mathrm{~min}$. The Savannah ALD from Cambridge NanoTech was used to perform 
the deposition [24]. The system is a thermal deposition system that uses surface adsorption of single mono-layers of reactive precursor gases to form single atomic monolayers. The samples were passivated with SiN by depositing $60 \mathrm{~nm}$ of SiN using the Plasma Enhanced Chemical Vapor Deposition (PECVD) technique. The composition of silicon nitride is $\mathrm{Si}_{3} \mathrm{~N}_{4}$. Finally, a set of samples were treated with $\mathrm{SiO}_{2}$ by depositing $100 \mathrm{~nm}$ of $\mathrm{SiO}_{2}$ using the thermal oxidation technique.

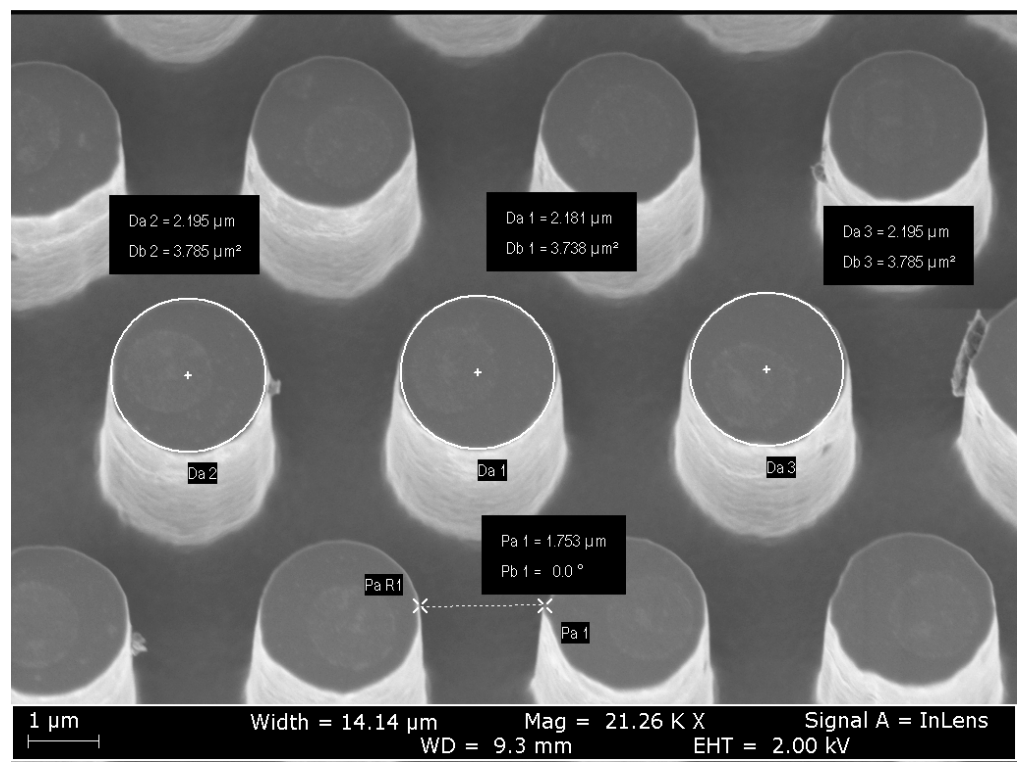

Figure 1. Silicon micropillars etched using the Reactive Ion Etching (RIE) method. The diameter of the pillars is $2.2 \mu \mathrm{m}$.

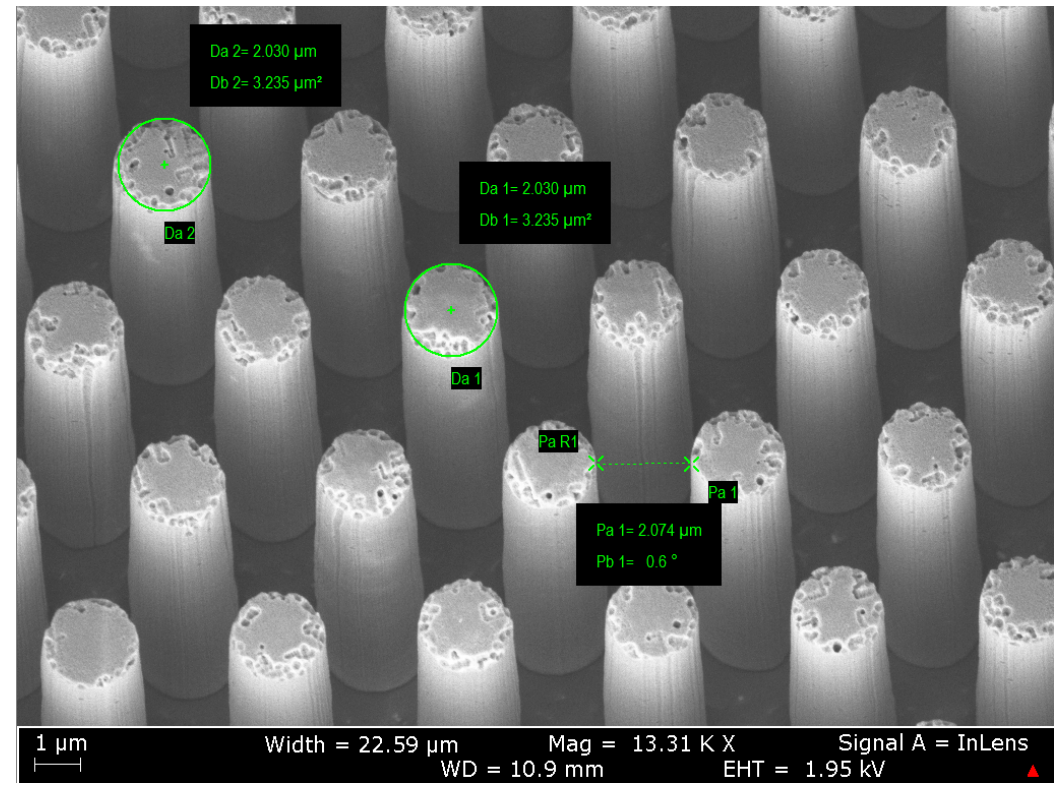

Figure 2. Silicon micropillars etched using the Metal Assisted Chemical Etching (MACE) method. The diameter of the pillars is $2 \mu \mathrm{m}$.

\section{Results}

The carrier lifetimes of the treated samples were studied using microwave PCD ( $\mu$ PCD) which is a Semilab tool that allows carrier lifetime using microwaves to be measured [25]. The results are presented in multiple figures that depict the average carrier lifetime of a plane silicon wafer (total area of the wafer is $1 \mathrm{~cm}^{2}$ ), an RIE micropillar silicon wafer, and a MACE micropillar silicon wafer. Figure 3 
presents the carrier lifetime of an untreated sample (dark grey) and a sample treated with $\mathrm{Al}_{2} \mathrm{O}_{3}$ (light grey). It is observed that the average carrier lifetime of a planar sample is $10.7 \mu \mathrm{s}$. The average carrier lifetime of a sample with micropillars etched using the reactive ion etching technique is $1.92 \mu$ s and a sample with micropillars etched using the Metal Assisted Chemical Etching technique is $9.86 \mu \mathrm{s}$.

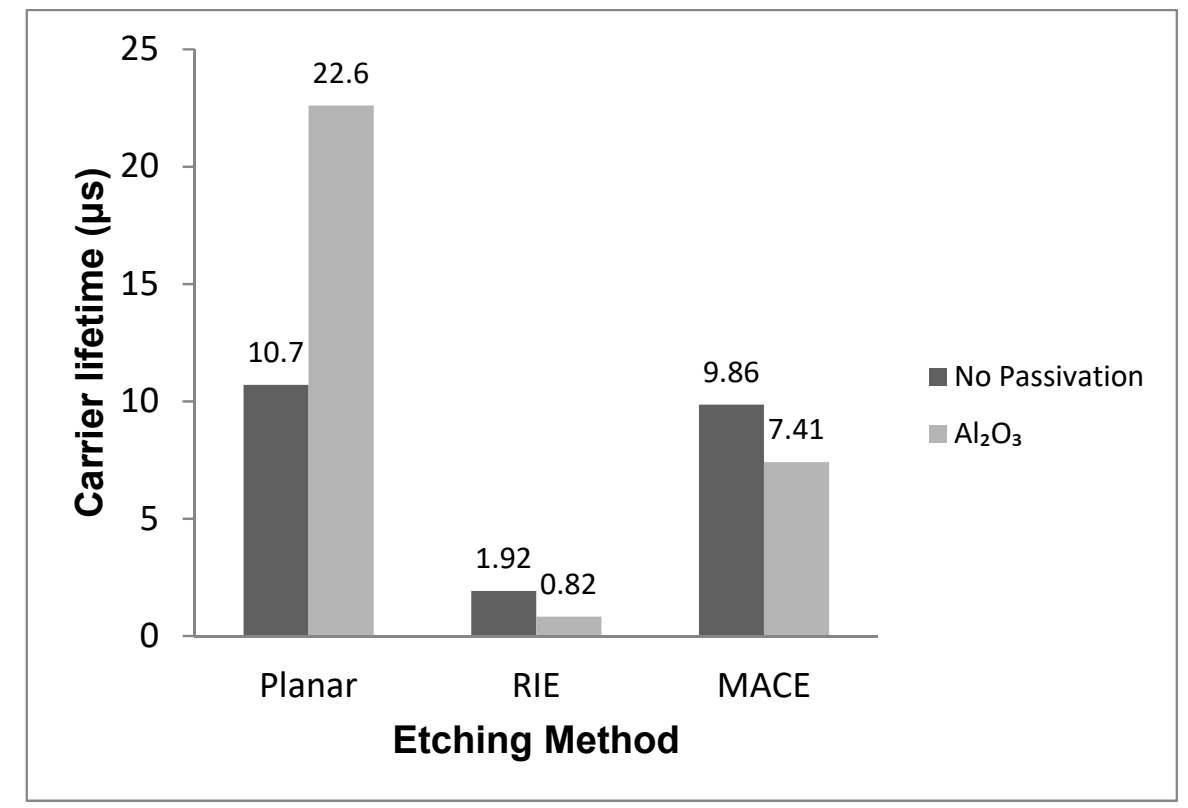

Figure 3. The carrier lifetime of the untreated samples and the samples treated with $\mathrm{Al}_{2} \mathrm{O}_{3}$.

The average carrier lifetime of the planar sample treated with $\mathrm{Al}_{2} \mathrm{O}_{3}$ is $22.6 \mu$ s which is an increase from the untreated planar. The RIE treated with $\mathrm{Al}_{2} \mathrm{O}_{3}$ sample has a lifetime of $0.82 \mu$ s which is a decrease in the lifetime from the non-treated RIE sample. The MACE sample also shows a decrease from $9.86 \mu \mathrm{s}$ to $7.41 \mu \mathrm{s}$ in its lifetime when treated with $\mathrm{Al}_{2} \mathrm{O}_{3}$.

Figure 4 presents the results of the samples treated with $\mathrm{KOH}$. The average carrier lifetime of the planar sample is $7.33 \mu \mathrm{s}$ which is a decrease from the untreated planar sample. The RIE treated with $\mathrm{KOH}$ sample has a lifetime of $0.92 \mu$ s which is a decrease in the lifetime from the untreated RIE sample. The MACE sample also shows a decrease from $9.86 \mu$ s to $6.38 \mu$ s in its lifetime when treated with $\mathrm{KOH}$.

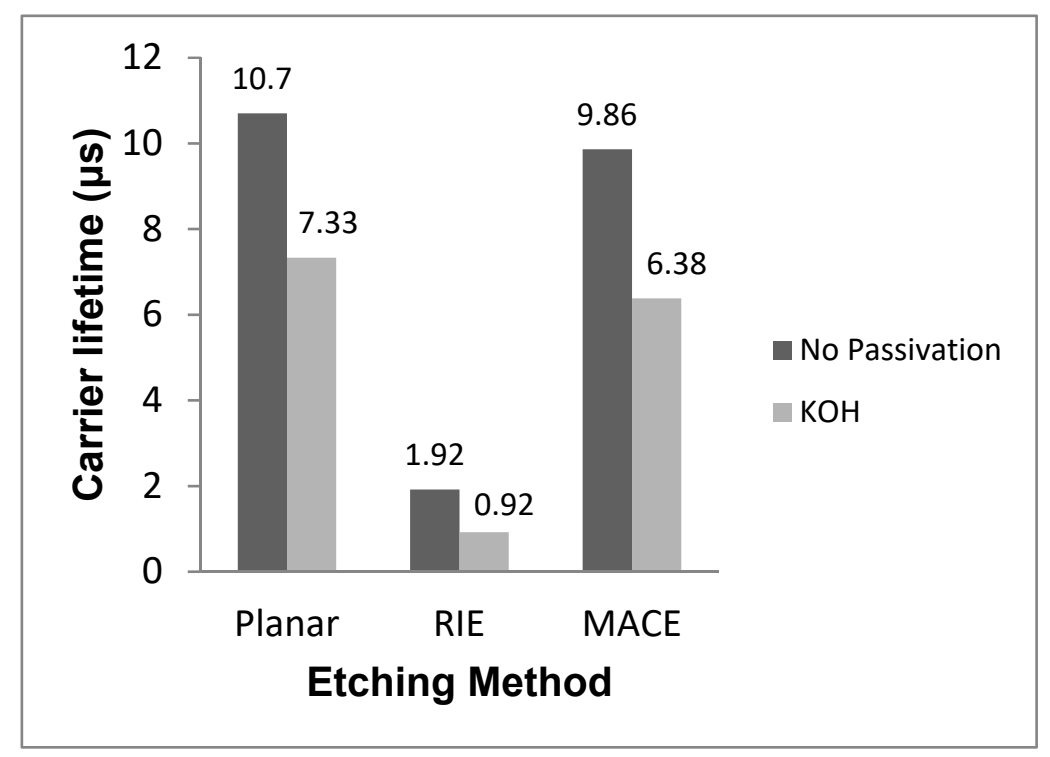

Figure 4. The carrier lifetime of the untreated samples and the samples treated with $\mathrm{KOH}$. 
Figure 5 presents the results of the samples treated with $\mathrm{SiO}_{2}$. The average carrier lifetime of the planar sample is $7.23 \mu$ s which is a decrease from the untreated planar sample. The untreated RIE sample has a carrier lifetime of $1.92 \mu \mathrm{s}$ and the RIE sample treated with $\mathrm{SiO}_{2}$ has a carrier lifetime of $0.98 \mu \mathrm{s}$. The MACE sample also shows a decrease from $9.86 \mu$ s to $8 \mu$ s in its lifetime when treated with $\mathrm{SiO}_{2}$.

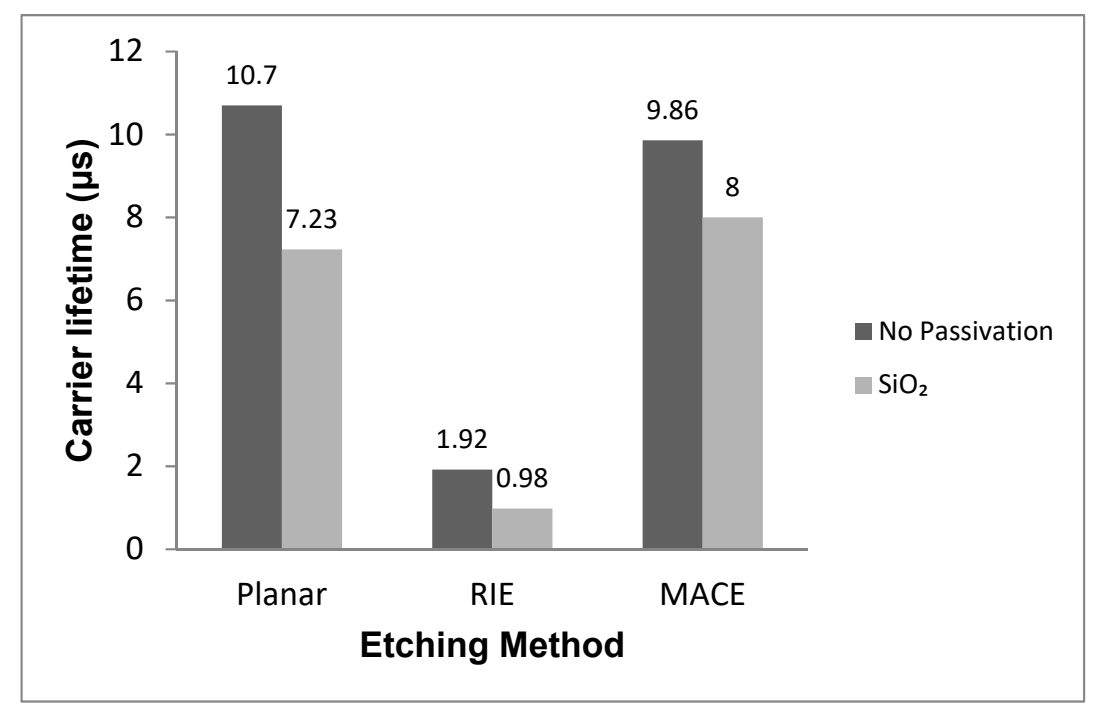

Figure 5. The carrier lifetime of the untreated samples and the samples treated with $\mathrm{SiO}_{2}$.

Figure 6 presents the results of the samples treated with SiN. The average carrier lifetime of the planar sample is $4.73 \mu \mathrm{s}$ which is a decrease from the untreated planar sample. The untreated RIE sample has a carrier lifetime of $1.92 \mu \mathrm{s}$ and the RIE sample treated with $\mathrm{SiN}$ has a carrier lifetime of $8.22 \mu \mathrm{s}$. The MACE sample also shows a decrease from $9.86 \mu$ s to $1.72 \mu \mathrm{s}$ in its lifetime when treated with SiN.

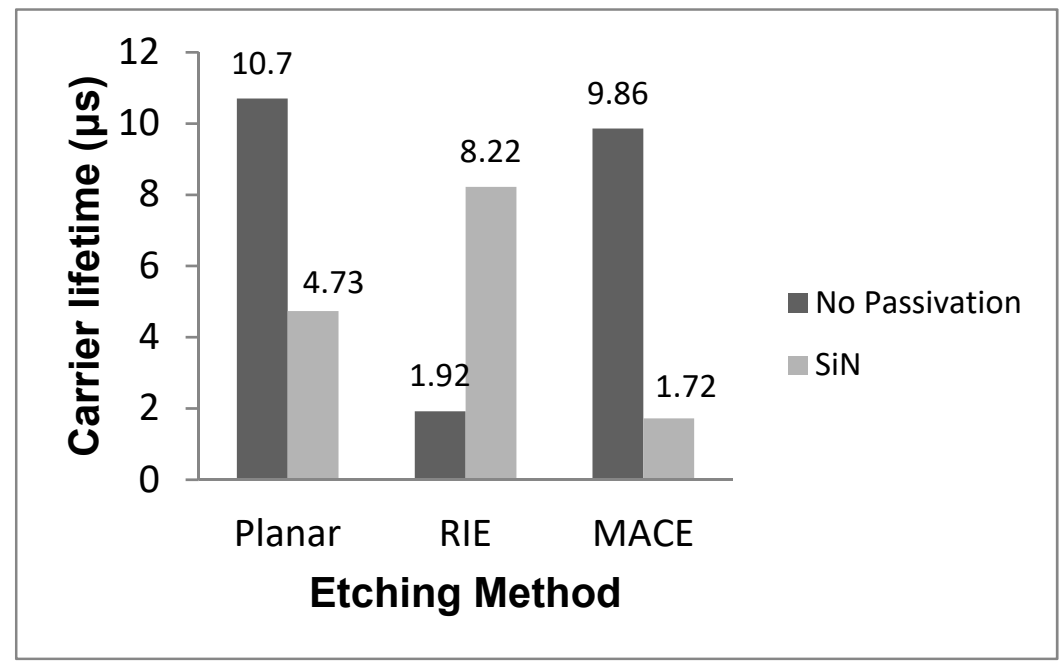

Figure 6. The carrier lifetime of the untreated samples and the samples treated with SiN.

Figure 7 presents the results of the samples treated with $\mathrm{SiO}_{2}$ and $\mathrm{SiN}$. The average carrier lifetime of the planar sample is $17.75 \mu$ s wich is an increase from the untreated planar sample. The untreated RIE sample has a carrier lifetime of $1.92 \mu$ and the RIE sample treated with $\mathrm{SiO}_{2} / \mathrm{SiN}_{\mathrm{N}}$ has a carrier lifetime of $14.62 \mu \mathrm{s}$. The MACE sample shows an increase from $9.86 \mu \mathrm{s}$ to $11.09 \mu \mathrm{s}$ in its lifetime when treated with $\mathrm{SiO}_{2} / \mathrm{SiN}$. Table 1 presents the mapping of the carrier lifetime over the area of the wafer. The table shows the average carrier lifetime in each sample. The second row indicates the mapping of the carrier lifetime over the surface area of the sample. 


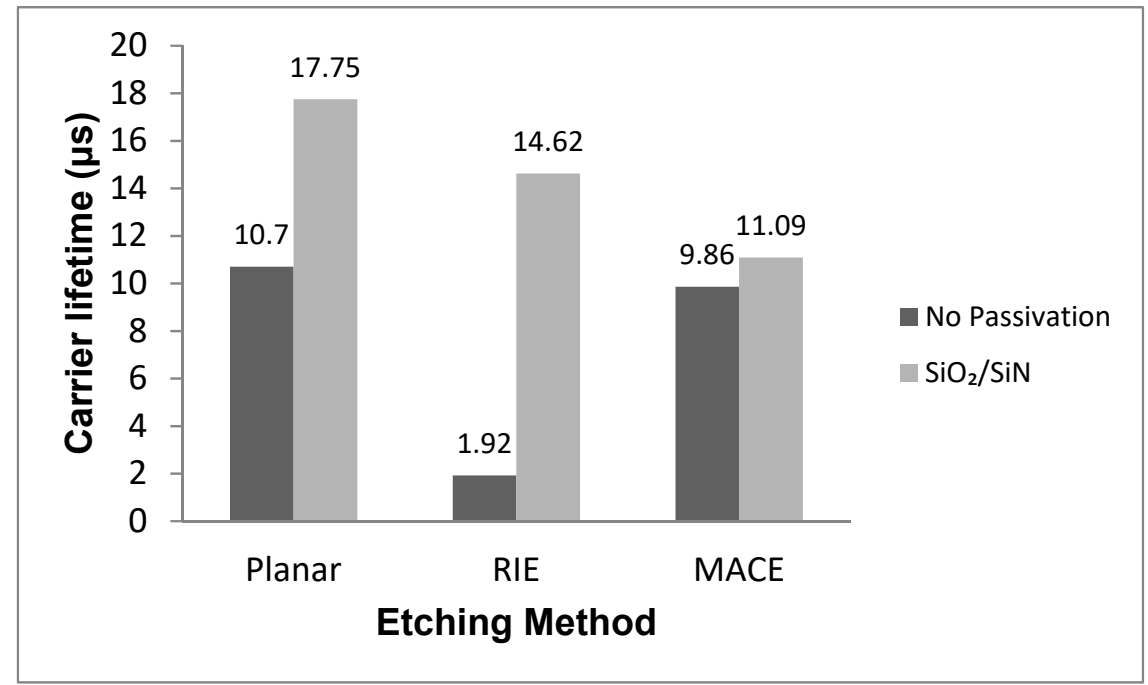

Figure 7. The carrier lifetime of the untreated samples and the samples treated with $\mathrm{SiO}_{2} / \mathrm{SiN}$

Table 1. Mapping of the Carrier Lifetime of a sample passivated with $\mathrm{SiO}_{2} / \mathrm{SiN}$.

\begin{tabular}{llll}
\hline $\begin{array}{l}\text { Average } \\
\text { Carrier } \\
\text { Lifetime }\end{array}$ & Planar & RIE & MACE \\
\hline Image & $17.8 \mu \mathrm{s}$ & $11.1 \mu \mathrm{S}$ \\
\hline Histogram & & & \\
\hline
\end{tabular}

\section{Discussion}

The measurements above show the effective minority carrier lifetime $\left(\tau_{\text {eff }}\right)$ that was obtained for the different passivation cases. It should be noted that back surface passivation was not performed in this experiment which is a reason for the low carrier lifetime readings of the samples, thus the reading gives only an indication of the front lifetime. The minority carrier lifetime could be expressed as [26]:

$$
\frac{1}{\tau_{e f f}}=\frac{1}{\tau_{b u l k}}+\frac{\left(S_{e f f}^{F}+S_{e f f}^{B}\right)}{d}
$$

where $\tau_{\text {bulk }}$ is the bulk Shockley-Read-Hall (SRH) lifetime, $S_{e f f}^{F}$ and $S_{e f f}^{B}$ are the effective surface recombination velocity at the front surface and at the back surface, respectively, and $d$ is the wafer thickness. It has been demonstrated that by increasing the surface area the front surface recombination velocity increases [26]. Since the combination of $\mathrm{SiO}_{2} / \mathrm{SiN}$ provided the highest carrier lifetime, this means that it provided the lowest surface recombination velocity. Previous results have 
demonstrated that $\mathrm{SiO}_{2}$ passivation reduces the $\mathrm{Si}_{-} \mathrm{SiO}_{2}$ interface state density which improves the surface recombination [27]. It has been also noted that high Auger recombination near the surface plays a key role in the lifetime of the carriers [27]. The RIE and MACE processes lead to dislocation and dangling bonds which also lead to severe Shockley-Read-Hall (SRH) recombination [27]. Thus the high recombination (low carrier lifetime) is due to surface, Auger, and $\mathrm{SRH}$ recombination. $\mathrm{SiO}_{2}$ passivates the surface and $\mathrm{SiN}$ provides bulk passivation because during the deposition of $\mathrm{SiN}$, hydrogen, which is found in the deposition chamber, diffuses in the material. The presence of hydrogen reduces the defect state density and suppresses the Auger recombination near the surface and the SRH recombination in the bulk of the material. Thus, when $\mathrm{SiO}_{2}$ and $\mathrm{SiN}$ are deposited together the highest carrier lifetime is obtained since the surface dislocations are passivated by $\mathrm{SiO}_{2}$ and the dangling bonds in the bulk of the material bond with hydrogen due to SiN deposition. It also must be noted that in almost all of the measurements the MACE pillars had a carrier lifetime greater than the RIE pillars and this is due to the fact that the micropillar surface formed by RIE may be damaged as a result of the plasma. However, the MACE process results in less damage especially when the ratio of $\mathrm{HF}$ and $\mathrm{H}_{2} \mathrm{O}_{2}$ is controlled [28].

\section{Conclusions}

The above samples were treated with different methods and it was shown that depositing SiN and $\mathrm{SiO}_{2}$ on a planar and micro structured sample with two different methods increases the lifetime of the sample. Surface passivation of the back of the sample was not performed and is recommended in the future. It is suggested that this method be used for surface recombination treatments.

Funding: This research received was partially funded by internal grants from Bucknell University.

Conflicts of Interest: The authors declare no conflict of interest. The funders had no role in the design of the study; in the collection, analyses, or interpretation of data; in the writing of the manuscript, and in the decision to publish the results.

\section{References}

1. Yoon, H.P.; Yumen, Y.A.; Shen, H.; Podraza, N.J;; Mallouk, T.E.; Dickey, E.C.; Redwing, J.A.; Wronski, C.R.; Mayer, T.S. Parametric study of micropillar array solar cells. In Proceedings of the 37th IEEE Photovoltaic Specialists Conference, Seattle, WA, USA, 19-24 April 2011; pp. 000303-000306. [CrossRef]

2. Shieh, J.; You, C.Y.; Liu, J.M.; Chiu, C.C. Improving optical and electrical properties of micropillar and black-Si solar cells by combining them into a superstructure. In Proceedings of the 23rd International Workshop on Active-Matrix Flatpanel Displays and Devices (AM-FPD), Kyoto, Japan, 6-8 July 2016; pp. 222-224. [CrossRef]

3. Ha, J.; Lee, S.W.; Lee, H.-J.; Lee, H.-J.; Lee, S.H.; Goto, H.; Kato, T.; Fujii, K.; Cho, M.W.; Yao, T. The fabrication of vertical light-emitting diodes using chemical lift-off process. IEEE Photonics Technol. Lett. 2008, 20, 175-177. [CrossRef]

4. Conway, A.M.; Wang, T.F.; Deo, N.; Cheung, C.L.; Nikolic, R.J. Numerical simulations of pillar structured solid state thermal neutron detector: Efficiency and gamma discrimination. IEEE Trans. Nucl. Sci. 2009, 56, 2802-2807. [CrossRef]

5. Gerasopoulos, K.; Pomerantseva, E.; McCarthy, M.; Culver, J.; Wang, C.; Ghodssi, R. A hierarchical approach for the fabrication of three-dimensional microbattery electrodes. In Proceedings of the 2011 16th International Solid-State Sensors, Actuators and Microsystems Conference, Beijing, China, 5-9 June 2011; pp. 727-730. [CrossRef]

6. Tsakalakos, L.; Balch, J.; Fronheiser, J.; Korevaar, B.A.; Sulima, O. Silicon nanowire solar cells. Appl. Phys. Lett. 2007, 91, 233117. [CrossRef]

7. Muskens, O.L.; Rivas, J.G.; Algra, R.E.; Bakkers, E.P.; Lagendijk, A. Design of light scattering in nanowire materials for photovoltaic applications. Nano Lett. 2008, 8, 2638-2642. [CrossRef]

8. Zhu, J.; Yu, Z.; Burkhard, G.F.; Hsu, C.M.; Connor, S.T.; Xu, Y.; Wang, Q.; McGehee, M.D.; Fan, S.; Cui, Y. Optical absorption enhancement in amorphous silicon nanowire and nanocone arrays. Nano Lett. 2009, 9, 279-282. [CrossRef] [PubMed] 
9. Kelzenberg, M.D.; Boettcher, S.W.; Petykiewicz, J.A.; Turner-Evans, D.B.; Putnam, M.C.; Warren, E.L.; Spurgeon, J.M.; Briggs, R.M.; Lewis, N.S.; Atwater, H.A. Enhanced absorption and carrier collection in si wire arrays for photovoltaic applications. Nat. Mater. 2010, 14, 239-244. [CrossRef]

10. Zhu, J.; Hsu, C.M.; Yu, Z.; Fan, S.; Cui, Y. Nanodome solar cells with efficienct light management and self-cleaning. Nano Lett. 2010, 10, 1979-1984. [CrossRef] [PubMed]

11. Gharghi, M.; Fathi, E.; Kante, B.; Sivoththaman, S.; Zhang, X. Heterojunction silicon microwire solar cells. Nano Lett. 2012, 12, 6278-6282. [CrossRef]

12. Park, W.I.; Zheng, G.; Jiang, X.; Tian, B.; Lieber, C.M. Controlled synthesis of millimeter-long silicon nanowires with uniform electronic properties. Nano Lett. 2008, 8, 3004-3009. [CrossRef]

13. Xu, T.; Tao, Z.; Li, H.; Tan, X.; Li, H. Effects of deep reactive ion etching parameters on etching rate and surface morphology in extremely deep silicon etch process with high aspect ratio. Adv. Mech. Eng. 2017, 9, 1-12. [CrossRef]

14. Liu, S.; Niu, X.; Shan, W.; Lu, W.; Zheng, J.; Li, Y.; Duan, H.; Quan, W.; Han, W.; Wronski, C.R.; Yang, D. Improvement of conversion efficiency of multicrystalline silicon solar cells by incorporating reactive ion etching texturing. Sol. Energy Mater. Sol. Cells 2014, 127, 21-26. [CrossRef]

15. Qian, H.X.; Zhou, W.; Miao, J.; Lim, L.; Zeng, X.R. Fabrication of Si microstructures using focused ion beam implantation and reactive ion etching. J. Micromech. Microeng. 2008, 18, 035003. [CrossRef]

16. Miller, K.; Li, M.; Walsh, K.M.; Fu, X. The effects of DRIE operational parameters on vertically aligned micropillar arrays. J. Micromech. Microeng. 2013, 23, 035039. [CrossRef]

17. Li, X.; Xiao, Y.; Bang, J.; Lausch, D.; Meyer, S.; Miclea, P.; Jung, J.; Schweizer, S.; Lee, J.; Wehrspohn, R. Upgraded silicon nanowires by metal-assited etching of metallurgical silicon: A new route to nanostructured solar-grade silicon. Adv. Mater. 2013, 25, 3187-3191. [CrossRef]

18. Huang, Z.; Geyer, N.; Werner, P.; Boor, J.; Gosele, U. Metal-assisted chemical etching of silicon: A review. Adv. Mater. 2011, 23, 285-308. [CrossRef] [PubMed]

19. Henry, M.; Walavalkar, S.; Homyk, A.; Scherer, A. Alumina etch masks for fabrication of high-aspect-ratio silicon micropillars and nanopillars. Nanotechnology 2009, 20, 255305-255309. [CrossRef]

20. Sainiemi, L.; Nissilä, T.; Jokinen, V.; Sikanen, T.; Kotiaho, T.; Kostiainen, R.; Ketola, R.; Franssila, S. Fabrication and fluidic characterization of silicon micropillar array electrospray ionization chip. Sens. Actuators B 2018, 132, 380-387. [CrossRef]

21. Kilchenmann, S.; Rollo, E.; Bianchi, E.; Guiducci, C. Metal-coated silicon micropillars for freestanding 3D-electrode arrays in microchannels. Sens. Actuators B 2013, 185, 713-719. [CrossRef]

22. Shin, J.C.; Chanda, D.; Chern, W.; Yu, K.; Rogers, J. Experimental study of design parameters in silicon micropillar array solar cells produced by soft lithography and metal-assisted chemical etching. IEEE J. Photovoltaics 2012, 2, 129-133. [CrossRef]

23. Li, X.; Bohn, W.P. Metal-assisted chemical etching in $\mathrm{HF} / \mathrm{H}_{2} \mathrm{O}_{2}$ produces porous silicon. Appl. Phys. Lett. 2000, 77, 2572-2574. [CrossRef]

24. Veeco Instruments. Savannah-Thermal ALD for R\&D. Available online: http://www.cambridgenanotechald. com/products/Savannah-ald-system.shtml (accessed on 12 April 2019).

25. Semilab Inc. $\mu$-PCD Carrier Lifetime for Wafers. Available online: https://www.semilab.hu/category/ products/u-pcd-carrier-lifetime-wafers (accessed on 12 April 2019).

26. Lin, X.; Hua, X.; Huang, Z.; Shen, W. Realization of high performance silicon nanowire based solar cells with large size. Naotechnology 2013, 24, 235402-235410. [CrossRef] [PubMed]

27. Oh, J.; Yuan, H.-C.; Branz, H.M. An 18.2\%-efficiency black-silicon solar cell achieved through control of carrier recombination in nanostructures. Nat. Nano. 2012, 7, 743-748. [CrossRef] [PubMed]

28. Toan, N.V.; Toda, M.; Ono, T. High aspect ratio silicon structures produced via metal assisted chemical etching and assembly technology for cantilever fabrication. IEEE Trans. Nanotechnol. 2017, 16, 567-573. [CrossRef]

(C) 2019 by the author. Licensee MDPI, Basel, Switzerland. This article is an open access article distributed under the terms and conditions of the Creative Commons Attribution (CC BY) license (http://creativecommons.org/licenses/by/4.0/). 